\title{
EL LABERINTO DEL VISADO COMO INSTRUMENTO JURÍDICO DE LA UNIÓN EUROPEA. UN EJEMPLO DE NO MODELO PARA UNASUR
}

\author{
The laberinth of visas as a legal instrument of the european union. \\ A pattern to avert by UNASUR
}

Antonio MUÑOZ AUNIÓN ${ }^{1}$

\begin{abstract}
Sumario:
1. Introducción. 2. La cuestión de la conveniencia del visado de corta duración. 3. La regulación comunitaria en materia de visados. 4. Modelo uniforme de visados 5. La incipiente regulación unasur en materia migratoria. 6. Conclusiones. 7. Bibliografía.
\end{abstract}

Resumen: Fueron necesarios treinta años para que Europa fuera percibida como una entidad con fronteras exteriores comunes y regida por principios aduaneros y de vigilancia personal regulada por una suerte de modelo federal en progresión y que concede una gran visibilidad a la Unión Europea por cuanto al simbolismo. Este modelo por su rigidez y otras falencias quizás no sea apropiado para la Unión de Naciones Sudamericanas cuyo contexto como ideal de Unión es, no obstante común, pero si puede resultar un instrumento útil para abrir el debate de una integración mediante la creación de valores y símbolos comunes, facilitando el paso a una integración más profunda.

Palabras claves: Visados comunes, gestión migratoria, ciudadanía, integración, UNASUR, Unión Europa

\begin{abstract}
It took thirty years before Europe was perceived as an entity with common external borders governed by laws on customs and personal surveillance regulated by an embryonic federal model still in progression bringing about a great visibility to the EU by the strong symbolism at the port of entry. This model for its rigidity and other shortcomings may not be appropriate for the Union of South American Nations, in a context that is varied but whose ideal of Union is nevertheless common, still it can be a useful tool to crack up the debate on integration by creating values and common symbols clearing the path for in depth integration.
\end{abstract}

Keywords: Common visas, migration control, citizenship, integration, UNASUR, European Union

\section{PALABRAS PREVIAS}

El tema del visado ha sido abiertamente debatido; se ha sugerido que el visado representa la soberanía estatal y que, muy posiblemente, quedase aferrado al control estatal. ${ }^{2}$

\footnotetext{
${ }^{1}$ Doctor en Derecho Internacional Público y Europeo por la Universidad Carlos III de Madrid.

${ }^{2}$ WEIL, P.; defend son approche "consensuelle" de l'inmigration" Le Monde (Paris) 8 agosto 1997 p. 6. Así, la soberanía se basa hoy día en el concepto de la democracia mediante la cual los ciudadanos ejercitan sus derechos eligiendo a sus representantes y define la relación entre derechos de los ciudadanos y de los extranjeros
} 
A pesar de que el Tratado de Ámsterdam preveía que los asuntos de visado eventualmente, se transfirieran a la jurisdicción comunitaria, se conciben propuestas de más modestas ambiciones, como por ejemplo, la armonización de los estándares de visado. De hecho, los avances en armonización de visados son numerosos; primero, los Estados de la UE, como veremos, han desarrollado listas de Estados cuyos nacionales requieren visados y cuáles no. Es de destacar que al igual que "las listas de Estados seguros" los Estados han fracasado al no alcanzar una lista única. Las razones para ello son similares a las de las listas de Estados seguros. Cada Estado tiene sus propias consideraciones políticas vinculadas a las decisiones a adoptar en materia de inmigración. Segundo, la estandarización técnica de las etiquetas de visados (indicando la duración y la naturaleza de la estancia) se ha producido, aunque su ámbito no es global. Tercero, se ha desarrollado un sistema de comunicación unificado a nivel europeo, que une a las autoridades dentro del marco SIS, (actual SIS II) ${ }^{3}$ y Cuarto, un número de reajustes en la práctica de los visados se ha producido, en particular, respecto de los requisitos para la concesión de visados.

Conceptualmente, el visado es toda autorización concedida por un Estado miembro que autoriza a una persona a entrar en su territorio, siempre que se cumplen los requisitos de entrada y es válido para una estancia no superior a tres meses durante un período de seis meses a partir de la fecha de la primera entrada (visado de entrada); autoriza a una persona a atravesar su territorio o a estar en la zona de tránsito (visado de tránsito); o autoriza a una persona que ya se encuentra en su territorio a volver a ese país dentro de un plazo determinado (visado de regreso)". ${ }^{4}$

Estas medidas muestran claramente una estandarización de las políticas de visados, más que un deslizamiento hacia la comunitarización. Además, la estandarización sólo cubre ciertos tipos de visados de corta duración y "no se ha realizado ningún esfuerzo para reducir el número elevado de visados nacionales, a unos pocos que concedan los mismos privilegios en todos los Estados miembros".

Aunque estos objetivos están lejos de la política de comunitarización, se espera que ponga fin a la emigración secundaria, al asegurar que los órganos de control de fronteras se encuentren en posición para llevar a cabo controles efectivos en un área interna en la que no hay controles.

Pasamos a analizar la situación en la que se encuentra la Unión Europea en esta materia y los progresos realizados.

en un Estado democrático, véase, NAFZINGER, J.; “The General Admission of Aliens under International Law" American Journal of International Law vol. 77/41. pp. 804-847.

3 En este punto, un número de expertos comunitarios cuestionan la eficacia de tales acciones, tras haber entrevistado a funcionarios de inmigración en Francia (aeropuerto Charles de Gaulle) y el Reino Unido (aeropuerto de Heathrow) un analista político sostenía que las autoridades percibían una gran separación entre sus prácticas y las de sus colegas europeos del otro lado del Canal. La simple comunicación y los asuntos de coordinación presentan retos al control de la migración interestatal.

4 Artículo 11 del Convenio de Aplicación del Acuerdo de Schengen; artículo 1 de la Propuesta de Convenio relativo al control de las personas en el cruce de las fronteras exteriores y artículo 3 de la Propuesta de Reglamento por el que se determinan los terceros países cuyos nacionales deben estar provistos de un visado al cruzar las fronteras exteriores de los Estados miembros. 


\section{INTRODUCCIÓN}

El mecanismo tradicional de control de acceso al territorio bajo la soberanía de un Estado, es el del visado emitido ${ }^{5}$ en el país de origen por la oficina diplomática del país de destino.

En la década de los Ochenta existía una proyecto de lista común de países que necesitaban visado para entrar en la Comunidad Europea producto de la Cooperación Intergubernamental Trevi. ${ }^{6}$ Este visado permitiría una estancia de corta duración máxima de tres meses, en el conjunto del territorio de la Unión. ${ }^{7}$ Debido a la creación de un espacio común, la Unión Europea se ha visto empujada a comunitarizar su política en materia de visados: con la creación de una lista de Estados terceros cuyos nacionales deben tener un visado para acceder al territorio ${ }^{8}$ y la puesta en funcionamiento de un modelo uniforme para los Quince Estados miembros de la Unión.

La armonización no es completa en la medida en qué cada Estado podía añadir a la lista común algunos Estados terceros cuyos nacionales debían disponer de un visado para entrar en su territorio. Teniendo en cuenta este aspecto, la política común de visados tiene una eficacia muy limitada considerando que los Estados han hecho uso de esta facultad. ${ }^{9}$

5 El visado es una autorización que cada Estado concede a los nacionales de los otros Estados para que puedan entrar en su territorio y permanecer en él por un período de tiempo determinado, bajo unas ciertas condiciones y cumpliendo una serie de requisitos. Nuestra Ley Orgánica 7/85 indicaba en su artículo 12: "Los pasaportes y títulos de viaje de los extranjeros que pretendan entrar en territorio español deberán ir provistos del correspondiente visado, salvo lo dispuesto en las leyes internas o en los tratados internacionales de los que España sea parte. El visado será expedido por las Representaciones diplomáticas y Oficinas Consulares de España y habilita al extranjero para presentarse en un puesto fronterizo español y solicitar su entrada. Para la concesión del visado se atenderá al interés del Estado español y de sus nacionales, en los términos previstos reglamentariamente". Ley Orgánica de Derechos y Libertades de los Extranjeros en España de 1 de julio de 1985 derogada por Ley Orgánica 4/200o de 11 de enero sobre derechos y libertades de los extranjeros en España y su integración social.

6 Requisito de visados para 50 Estados. Un Proyecto de Armonización de los sistemas de visados de entrada en los países CEE WITHOL DE WENDEN, C.; "Refugié politique: une notion en crise". Esprit mayo 1990 p. 79

7 Desde 1992 existe una Declaración del Comité Ejecutivo sobre la habilitación para la expedición de visados uniformes (Doc. SCH/M (92) 23 de 15 de diciembre de 1992) habilitándose como regla general a las Misiones diplomáticas y las Oficinas Consulares de Carrera, si bien transitoria y excepcionalmente se permitió a los cónsules honorarios de los Estados del Benelux que, previa justificación aceptada por los demás Estados miembros, pudieran en casos excepcionales concretos conceder visados. A través de instrucciones comunes se puede recoger un conjunto de indicaciones para su expedición, prórroga, y denegación de conformidad con los intereses comunes de los Estados partes. En el marco de cooperación Schengen correspondía según el artículo 17 del Convenio de Aplicación de Schengen, al comité ejecutivo el desempeño de un papel relevante en el desarrollo efectivo de este conjunto de tareas.

8 La Unión Europea a través de esta política de visados, desplaza el control fuera de sus propias fronteras, por lo tanto inhibiéndose discretamente de posibles responsabilidades. Como el equilibrio entre control inmigratorio y protección de los refugiados está cambiando, - no es de extrañar que para casi cada país cuyos nacionales tendrían estadísticamente una petición bien fundada al estatuto de refugiado, requieran de visado - y el control se externaliza para desarrollarse fuera del país de destino, la responsabilidad, según el Derecho Internacional de Protección de los Derechos Humanos, en última instancia, puede terminar difuminándose.

9 El hecho de que esta lista común fuese menguando por las aportaciones de los Estados, dio como resultado esta sentencia de anulación del Tribunal de Justicia. Esto es, "la diferencia entre una verdadera lista común propuesta inicialmente por la Comisión, y una lista completada por listas nacionales adoptada por el Consejo, de forma indefinida, que permitía a los Estados miembros imponer visado a ciertos nacionales." Lo que justificó la anulación parcial por el TJCE del primer reglamento. Si bien, los efectos del Reglamento se mantuvieron hasta que el Consejo adoptará otro Reglamento. El Consejo no había tomado en consideración la observación del Parlamento sobre esta diferencia. Así, el Abogado General Fenelly, había apuntado en sus conclusiones: "El Consejo ha sustituido una propuesta de política comunitaria común y exclusiva en 
Asimismo, una política común de visados debería conllevar el reconocimiento mutuo de visados de corta duración emitidos por un Estado, en el resto de Estados de la Unión. Este reconocimiento mutuo estaba previsto en la propuesta inicial de Reglamento presentada por la Comisión. El Consejo no admitió este reconocimiento mutuo, al considerar que no podía realizarse en el marco del antiguo artículo $100 \mathrm{C}$, sin que se hubiese firmado con anterioridad la Convención sobre Fronteras Exteriores.

\section{LA CUESTIÓN DE LA CONVENIENCIA DEL VISADO DE CORTA DURACIÓN}

Las dificultades que vamos a encontrar en materia de visados nos lleva a preguntarnos sí no sería más conveniente, que una verdadera política común de visados no se debería reorientar hacia la supresión de los visados de corta duración. En primer lugar planteamos la cuestión de por qué la necesidad de visados para controlar las corrientes migratorias. Anunciado como un medio de control de las migraciones, la figura del visado plantea dos cuestiones de importancia: su razón de ser y su utilidad.

i) Respecto del primero, la existencia de una autorización previa a la entrada en el territorio difícilmente puede conciliarse con el derecho de toda persona a abandonar no importa qué país, comprendido el suyo, y así se encuentra en el artículo 12. 2 del Pacto Internacional sobre Derechos Civiles y Políticos y el artículo 2 del Protocolo 4 de la Convención Europea de Derechos Fundamentales. ${ }^{10}$

Desde el momento en que el mundo está dividido en más de 190 países, sería lógico que al derecho de abandonar un país le siguiese necesariamente el derecho de entrada en el territorio de otro país. Todavía no ha madurado el tiempo de extender la supresión de la autorización de salida a la supresión del visado de entrada.

La lógica no siempre se convierte en norma jurídica, y el Derecho internacional funda la diferencia entre el derecho a abandonar y la ausencia de un derecho similar de entrada, en base a la soberanía nacional: todo Estado es competente para regular el acceso de entrada a su territorio. ${ }^{11}$ Cabe preguntase sí la movilidad de las mercancías y de capitales unida a la movilidad de información, podrá acomodarse a los obstáculos a la movilidad de personas.

Nos referimos al ideal clásico de supresión del visado de corta duración, que conllevaría al reconocimiento de un derecho absoluto a toda persona de viajar durante un período máximo de tres meses por cualquier territorio, no de un derecho de residencia. En cierta manera es similar al derecho de hospitalidad reconocido por ENMANUEL KANT en 1795 en su proyecto de Paz Perpetua, ${ }^{12}$ en el mismo sentido GROCIO, VITORIA, WOLF o PUFFENDORF

materia de visados, en lo que el Parlamento había juiciosamente descrito como representativo del "mínimo común denominador” a saber, una lista comunitaria común que podría por otro lado, coexistir con 15 listas nacionales suplementarias, por la prevalencia de los intereses de los Estados. Conclusiones 20 de marzo 1997 STJCE 10 de junio de 1997 Parlamento c. Consejo (visados) coadyuvante Francia Asunto C- $392-95$ Rec. I p. 3213 cons. 28 .

${ }^{10}$ Firmado en Estrasburgo el 16 de septiembre de 1963 y en vigor desde el 2 de mayo de 1968. España no ha ratificado aún este Protocolo, que dispone: “(...) Toda persona tendrá derecho a salir libremente de cualquier país, incluso del propio. (...) Toda persona es libre de abandonar cualquier país, incluido el suyo” Derechos Humanos Selección Básica de Textos Internacionales (comp.) BOU FRANCH, V.; Tirant lo Blanch 2003 (...)

${ }^{11}$ Véase, opinión del Tribunal Supremo de los Estados Unidos, as. Kleindiest v. Mandel, 408 US 753,765 (1972) que se refiere a "principios ancestrales del Derecho Internacional de los pueblos a mantener la competencia del Gobierno para excluir a todos los extranjeros, sí así lo considera”.

${ }^{12}$ Sobre la propuesta de supresión de visados, ver JEAN-YVES CARLIER "Pour la suppression des visas du pas suspendu du gitan au temps des cignones; de la libre circulation á la circulation libre” Institut d'etudes 
que defendían un derecho a la libre emigración, a la estancia temporal y a la residencia permanente para los refugiados expulsados de sus hogares, siempre que los motivos para su admisión fueran legales.

ii) Pasamos a la segunda cuestión, la de la utilidad del visado de corta duración como mecanismo idóneo de control de las inmigraciones.

Si bien puede admitirse que en el estado actual de las relaciones económicas y demográficas mundiales, el control de las migraciones es un objetivo legítimo de interés general para algunos Estados o grupos de Estados, no es menos cierto que los visados no son el mecanismo más adecuado para alcanzar este objetivo. ${ }^{13}$ Así, la interrogante es la siguiente; puede el visado aprobar los dos test clásicos del principio de proporcionalidad: la eficacia y la necesidad del medio utilizado en vista a alcanzar un objetivo legítimo. El test de la eficacia plantea cuestiones: ¿el visado es realmente un mecanismo eficaz para combatir la inmigración irregular, al igual que como control de personas para la seguridad pública? Es poco probable, por un lado, los criminales internacionales y los terroristas generalmente disponen de todos los documentos y visados requeridos por las autoridades.

Por otro lado, lejos de disuadir la inmigración irregular, el visado la acentúa, frente a la dificultad de obtener un visado el ciudadano extranjero pasara a la inmigración clandestina, a merced de transportistas poco escrupulosos y corriendo riesgos de perecer en el camino. Una vez introducido clandestinamente, o una vez obtenido, difícilmente, el visado, el extranjero se instalará en la clandestinidad más allá de las estancias turísticas (3 meses) con el temor a no poder regresar en el caso de que vuelva a su país de origen. Lo prohibido refuerza la atracción de El Dorado mítico.

La dificultad de obtener un visado incrementa, de igual forma, con la finalidad única de permitir la entrada en el territorio, las solicitudes de asilo manifiestamente infundadas; además, la dificultad de obtener un visado perjudica al turismo, a los viajes de negocios, a los intercambios culturales e intelectuales, a las visitas familiares, y conlleva a unos tratos degradantes para aquellos que solicitan al esperar horas, e incluso días, largas colas para someterse a los controles predeterminados. ${ }^{14}$

Si la eficacia del visado resulta dudosa, su necesidad lo es aún más. El examen de la necesidad puede traducirse en un test de intercambiabilidad: ¿no existe otro medio más que el visado que permita alcanzar el mismo objetivo legítimo (de control de las migraciones) sin ocasionar un perjuicio tan elevado a los derechos fundamentales. De manera general, el control de identidad seguiría en vigor, y la autorización previa seguiría siendo necesaria para las estancias de más de tres meses y para la residencia definitiva. A la entrada, el ciudadano extranjero estaría obligado a estampar un sello fechado en su pasaporte, a falta de éste, en

européennes UCL documents. 5, 1997.

${ }^{13}$ Para una valoración positiva del visado, PASTOR RIDRUEJO, “La desaparición de fronteras en la Europa comunitaria y los problemas demográficos e inmigratorios” ICE 1990 pp. 7; según el Profesor podría funcionar como una garantía de la entrada y la permanencia en el territorio común; una opinión distinta DEJONG, C. D.; "The Granting of Visas, Passports and Asylum and Refugee Status "en SCHERMERS, HENRY, G: HINTERMAN et al.; Free Movement of Persons in Europe. Legal Problems and Experiences. Dordrecht 1993 Resulta criticable su carácter restrictivo ya que, al ser las condiciones de su concesión las mismas que las de entrada, el visado funciona en la práctica como un control previa a la entrada, realizado en el momento en el que éste se solicita en los Estados de origen ante las autoridades diplomáticas o consulares del Estado miembro de destino.

${ }^{14}$ Por lo que se refiere a la expedición, el visado uniforme será expedido únicamente a la persona que cumple las condiciones de entrada, por las representaciones diplomáticas y consulares de los Estados miembros. En principio, será competente para expedir el visado el Estado miembro de destino principal. 
caso de control se presumirá que se encuentra en el territorio después de más de tres meses, a no ser que se encuentren en condiciones de aportar prueba en contrario (por ejemplo, a través de documentos de viaje).

Con este objetivo sería necesario acudir a una fase de transición, en la armonización de visados en la UE, en lugar de la pura y simple supresión de visado, por ejemplo, a través de la lista de los Estados terceros cuyos nacionales deben disponer de visado puede ser reducida de forma progresiva, pero regular.

Además, en el marco de la Unión Europea resulta difícil mantener la necesidad absoluta de visado como mecanismo de control de las migraciones cuando se constata que numerosos países de Europa Central y Oriental, han sido retirados de la lista común, a pesar de los temores a grandes migraciones provenientes del Este de Europa tras la caída del muro de Berlín.

Igualmente, en razón de los vínculos tradicionales de reciprocidad entre España y los países de América del Sur, todos estos países - con la excepción del Perú, en un primer momento, fueron retirados de la lista común (véase infra).

Como vemos, la reciprocidad puede ser una condición de supresión mutua del visado, este criterio al que recurrían los Estados individualmente y separadamente en el marco de las relaciones tradicionales de Derecho Internacional público, debe utilizarse en adelante teniendo en cuenta las exigencias de las relaciones exteriores de la UE con terceros países. De ahí que España volviera a incluir a ciertos países de América del Sur. Se corre el riesgo de que, con carácter general, la armonización de las políticas nacionales en materia de visados lleve aparejada la renuncia a los lazos históricos y políticos que justifican normalmente los acuerdos de exención de visados en el plano bilateral, que ahora pasan a negociarse en el marco del conjunto de los Estados miembros.

Una etapa intermedia consistiría en reemplazar el visado actual, condicionado y difícil de obtener, por una autorización de viaje incondicional, estampada de forma automática sobre el pasaporte por la representación diplomática en el país de origen. Esto permite, por un lado, contabilizar las solicitudes y controlar las entradas y salidas al país de destino; en el supuesto de salidas claramente inferiores a las entradas, el visado podría reinstaurarse, lo que permite también llamar la atención del visitante sobre sus limitados derechos: una estancia de tres meses máximo que no conlleva ni la entrada al mercado del empleo ni derechos sociales.

Consideramos que el visado de corta duración no puede ser utilizado como un mecanismo efi caz y necesario de controlar la inmigración, al contrario su suspensión conduce a reconocer un derecho absoluto a viajar, lejos de ser una fuente de emigración, esta movilidad es de una naturaleza tal que reduce la migración de instalación en beneficio del desplazamiento de corta duración.

Como objetivo para controlar a los refugiados económicos, los visados de corta duración minan el ejercicio práctico del derecho a solicitar asilo. ${ }^{15}$

Cuando existen estos requisitos de visado la entrada legal sólo puede ser obtenida mediante una solicitud previa de visado, no obstante, cuando en ciertos Estados se producen conflictos internos, o actos de represión que son motivos para solicitar asilo por el individuo, va a resultar muy poco factible para estos individuos la solicitud de un visado para entrar en un Estado de la Unión Europea.

\footnotetext{
${ }^{15}$ European Consultation on Refugees and Exiles. " A Refugee policy for Europe "en JOLY, D y COHEN, R.(eds) Reluctant Hosts: Europe and its refugees 1989 Avenvury p. 220
} 
Las críticas sobre una política de visados también se centran en los países seleccionados; ya que estos requisitos se han impuesto sobre aquellos países que son más proclives a producir refugiados. ${ }^{16}$ Además, se siguen mezclando los problemas del Asilo y de la inmigración ilegal, como muestra el Reglamento de visados de 1999, véase el énfasis en el Preámbulo en su primer punto al afirmar "en los que los peligros relativos a la seguridad y a la inmigración ilegal debe ser una prioridad para su consideración cuando se redacte la lista común”.

Finalmente, también es necesario recordar el principio de corriente igualatoria en una Unión Europea plenamente identificada con valores democráticos. Así, el Anexo de este Reglamento donde aparecen los Estados cuyos nacionales deben estar en posesión de visado al cruzar las fronteras exteriores de los Estados miembros [artículo 1]; el primero de ellos es Afganistán lo que muestra la ausencia de una perspectiva de igualdad. ${ }^{17} \mathrm{La}$ amplia violación de los derechos humanos en este país no necesita de corroboración o de testimonios, sobretodo en relación con la población femenina. Por ejemplo ACNUR informa que las mujeres tienen restringido el acceso al mercado laboral o educativo. ${ }^{18}$

Asimismo existen considerables indicios de violencia contra las mujeres, que incluyen castigos físicos por no llevar la burka. Los grupos homosexuales tampoco escapan estas olas de barbarie, y la sodomía está castigada por normas penales; en 1998 cinco hombres inculpados con sodomía fueron sentenciados a muerte. ${ }^{19}$

Frente a este panorama, la imposición de requisitos de visados en Afganistán plantea serias preocupaciones ya que impedirá a individuos que intentan escapar actos de persecución que lo hagan, además ignora la necesidad acuciante de ofrecer protección adecuada a aquellas mujeres que deseen abandonar el país.

\footnotetext{
${ }^{16}$ FEXETE, L Y WEBBER F, Inside Racist Europe 1994 Institute of Race Relations p. 29.

${ }^{17}$ Conocida en el Derecho anglosajón como corriente mainstreaming, en nuestra doctrina el Profesor MARTÍN ARRIBAS, J. J.; la define como políticas transversales, en Los Estados europeos frente al desafío de los refugiados y el derecho de asilo. Ed. Dykinson 200o. Según la Ley 5/1984 reguladora del derecho de asilo y de la condición de refugiado (Ley 9/1994 de 19 de mayo, los extranjeros que pretendan solicitar asilo encontrándose ya en territorio español deberán presentar su solicitud mediante una comparecencia personal ante la dependencia que corresponda. La entrada ilegal en territorio español no podrá ser sancionada cuando haya sido realizada por persona que reúna los requisitos propios de la condición de refugiado, siempre que se presente sin demora a las autoridades. La solicitud de asilo en el interior del territorio español habrá de presentarse en el plazo de un mes a contar desde la entrada en el mismo, salvo en los supuestos en que el extranjero disfrute de un período de estancia legal superior al citado, en cuyo caso podrá presentarse antes de la expiración del mismo.

${ }^{18}$ ACNUR, "Update to the background paper on refugees and asylum seekers from Afghanistan" Centre for Research and Documentation Geneva Enero 1999.

${ }^{19}$ Los castigos eran extravagantes si no inhumanos. En abril de 1998 a dos soldados sorprendidos en prácticas homosexuales los golpearon sin misericordia y entonces, atados, los pasearon por Kabul en una camioneta de caja descubierta, los rostros ennegrecidos con aceite de motor. Los hombres acusados de sodomía se enfrentaban al "castigo islámico", desconocido hasta entonces, de perecer bajo un muro que derriban sobre ellos. En febrero de 1998, a tres hombres condenados por sodomía en Kandahar les llevaron a la base de un enorme muro de barro y ladrillo, y por medio de un tanque, lo derribaron sobre ellos. En marzo de 1998 dos hombres fueron ejecutados por el mismo procedimiento en Kabul. "Nuestros expertos religiosos no se ponen de acuerdo sobre la clase de castigo adecuado a los homosexuales" dijo el mulá Mohammed Hassan, resumiendo así la clase de debates a que se dedicaban los taliban. "Algunos dicen que deberíamos llevar a esos pecadores al tejado de un edificio alto y arrojarlos al vacío, mientras otros opinan que deberíamos cavar un hoyo al lado de un muro, introducirlos y entonces derribar el muro encima de ellos". En AHMED RASHID Los Talibán El Islam, el petróleo y el nuevo "Gran juego" en Asia Central. Ed. Península 2002 pp. 224-225.
} 


\section{LA REGULACIÓN COMUNITARIA EN MATERIA DE VISADOS}

\subsection{LOS VISADOS COMUNITARIOS}

Aún aceptando esta denominación, siempre pueden existir interferencias provenientes del Segundo Pilar de la Política Exterior y de Seguridad Común (PESC).$^{20}$ Estas Medidas Comunitarias basadas en el artículo 100 C TCE ${ }^{21}$ por ejemplo, el Reglamento de Visados, fue denominado como producto de una cierta técnica de Sfumatto. En septiembre de 1995, el Consejo de la Unión Europea adoptó un Reglamento n. 2317/95 determinando aquellos terceros países cuyos nacionales debían estar en posesión de visado al cruzar las fronteras exteriores de los Estados miembros, presentado por la Comisión. ${ }^{22}$

Con anterioridad, la Comisión presentó un formato común de visados de corta duración de los Estados miembros y el Consejo lo adoptó en mayo de $1995 .{ }^{23}$

La historia legislativa del Reglamento muestra algunas fuentes de conflictos entre el artículo 100 C TCE y el Título VI TUE, que tienen su origen en lo que la Comisión denominó con acierto "el clarooscuro o sfumato" en la difícil frontera entre los aspectos comunitarios y aquellas áreas cubiertas por el Título VI TUE. ${ }^{24}$

Debido a la lentitud del proceso y el conflicto entre el Proyecto de Convenio de fronteras exteriores y el artículo $100 \mathrm{C}^{25}$ se adoptan soluciones de geometría variable como las de Schengen. Se mantenía distintas opiniones sobre la zona fronteriza entre el artículo $100 \mathrm{C} \mathrm{y}$ el Título VI, tanto la Comisión como el Consejo eran de la opinión de que los requisitos para conceder un visado recaen en el Título VI, pero el concepto de reconocimiento mutuo entiende se encuentra fuera del Tercer pilar. (Comisión) Mientras que el Parlamento entendía que ambas se encuentran en el Primer pilar.

Poco después de la entrada en vigor del Tratado de la Unión Europea, la Comisión presentó una propuesta de Reglamento para una lista conjunta y un texto revisado para la bloquea-

\footnotetext{
${ }^{20}$ Por ejemplo, como ocurre con la Posición Común del Consejo de 16 de junio de 2001 relativa a la prohibición de visado para los extremistas de la ERYM DOCE L 194 18.07.2001.

${ }^{21}$ El párrafo 1 de este artículo consagraba la exigencia de visado para traspasar las fronteras externas de la Comunidad, a pesar de que el Consejo necesitase para ello la unanimidad y que existiera cierto control del Parlamento, comunitarización que queda debilitada por la previsión del párrafo al disponer: "no obstante, si se diera una situación de emergencia de un tercer país que supusiera un riesgo de súbita afluencia de nacionales de dicho país a la Comunidad, el Consejo podrá, por mayoría cualificada, sobre la base de una recomendación de la Comisión, establecer, durante un período que no supere los seis meses, el requisito de visado para los nacionales de dicho país”. Como acertadamente criticaba, ESPADA RAMOS, M. L. “" Asilo e Inmigración en la Unión Europea. “ Revista de estudios políticos núm. 86 oct-dic. 1994, se trata de una exclusión apriorística a cualquier tipo de circunstancias de súbditos de determinados países y una regla de excepcional carácter defensivo ante situaciones de emergencia nacional en cualquier Estado tercero. En este contexto, no se distingue entre inmigración económica, asilados, o refugiados; la reacción es genérica y de finalidad defensiva. pp. 88. Véase. SAMARY, C. "Les murailles toujours plus élevées de la fortresse Europe" Le Monde Diplomatique (enero 1994) pp. 10- 11.

${ }^{22}$ Era de prever que dicha lista fuese elaborada al alza y que aquellos Estados que mantuviesen posiciones más fuertes impondrían sus criterios, tratándose de una repetición del experimento Schengen y representaba el primer paso de una política de inmigración de alcance comunitario.

${ }^{23}$ Reglamento 1683/95 (1995) DOCE L 164/ 1.

24 Informe de la Comisión sobre el Grupo de Reflexión Luxemburgo 1995 p. 53. COM (96) 90382.

${ }^{25}$ Finalmente este artículo se comunitariza y se introduce en el Espacio de Libertad Seguridad y Justicia y desaparece junto al artículo $100 \mathrm{D}$.
} 
da Convención sobre Fronteras Exteriores, ${ }^{26}$ con la base jurídica del artículo $100 \mathrm{C}$, como necesaria para la realización del mercado interior, y facilitar la libre circulación de personas.

Las opciones eran, o bien el establecimiento de una lista positiva, de ciudadanos de Estados que no necesitasen visados; o bien negativa; finalmente se acogió la lista negativa —más fácil de aceptar por los Estados- en la que se incluyó a un cierto número de países, y el reconocimiento mutuo de los distintos visados por cualquier Estado miembro, ${ }^{27}$ que suponía un elemento fundamental de la propuesta. La Comisión y el Parlamento entendían que el artículo $100 \mathrm{C}$ TCE concedía competencia para preparar una lista positiva, pero el Consejo no estaba de acuerdo, ya que la adopción de una lista positiva no estaba explícitamente incluida entre "los otros aspectos" de la armonización de políticas que el Consejo había dejado al Tercer pilar.

Además, se podría requerir una lista positiva de nacionales que no requirieran visados (lista positiva); para el Reglamento se entenderían por visados aquellos emitidos por tres meses; visados de tránsito para viajar por un Estado miembro o zonas de tránsito en un aeropuerto; y visados permitiendo a una persona entrar en el territorio de un Estado miembro por un tiempo determinado.

A primera vista, las interpretaciones del Consejo y del Parlamento parecen coherentes, ya que es ilógico suponer que un Reglamento establezca el reconocimiento mutuo de visados, mientras que un Convenio define los visados y establece las condiciones para dicho reconocimiento mutuo, aunque también era ingenuo pensar que existiese una división coherente de competencias en las sombras de los pilares de Tratado de la Unión Europea de Maastricht, lo que hemos denominado como Sfumatto. ${ }^{28}$

El Reglamento (CE) n 2317/95, ${ }^{29}$ finalmente adoptado, tuvo poco que ver con la propuesta de la Comisión, ${ }^{30}$ y todavía menos similitudes con por las reformas pedidas por el Parla-

\footnotetext{
${ }^{26}$ Véase supra.

${ }^{27}$ La Comisión consideraba que la capacidad para adoptar una lista negativa necesariamente implicaba la competencia para adoptar una lista positiva, aunque esto último no apareciera ni de forma expresa, ni implícita recogido en los Tratados constitutivos. Memorándum explicativo ... "el concepto del mercado interior del artículo $7 \mathrm{~A}$ y el artículo $100 \mathrm{C}$ se interpretaban en un sentido amplio que cubría la posibilidad de diseñar una lista positiva.

${ }^{28}$ Discusiones sobre competencias para adoptar una política de visados han surgido en otros momentos; por ejemplo, en la Acción conjunta sobre viajes escolares; la propuesta de la Comisión sobre la abolición de visados cuando crucen fronteras interiores, y la acción conjunta del Consejo sobre visados de tránsito para nacionales de ciertos Estados terceros. La posición jurídica de estos últimos es particularmente dudosa, a pesar de que el Reglamento de visados especifica que no regula los visados de tránsito, el Reglamento de formato de visado explícitamente se refiere a ellos (Reglamento 1683795; artículo 5 del Reglamento 2317/95 no mantiene de forma explícita que los visados de tránsito recaían en el Título VI TUE, aunque se puede inferir que el Consejo adoptó este parecer. Ciertamente, ninguna institución comunitaria o Estado miembro podía mantener de forma razonable que los visados de tránsito recayesen en el artículo $100 \mathrm{C}$ (3), y no en el artículo 100 C (1) TUE. Véase, REMIRO BROTONS, A. "La Naturaleza de la Comunidad Europea, sus Competencias, Instituciones, y Sistema de Adopción de Decisiones en el Proceso de Integración." www. CEFIR.org.uy/docs/ dto4/13remir1.html. "Más significativa todavía es la previsión por el TUE de puentes o pasarelas que pueden conducir a determinadas cuestiones en dirección única e irreversible de las formas de la cooperación intergubernamental a las Comunidades. Se pueden comunitarizar ya, sin revisar el tratado ciertos objetos de la cooperación, pero no se pueden, en principio, intergubernamentalizar los ámbitos comunitarizados".

${ }^{29}$ DOCE L 234, de 3. 10. 1995. P. 1.

${ }^{30}$ La Comisión redactó un Anexo con un listado de 126 países situados en la lista negra, con la obligación de alcanzarse un acuerdo sobre la lista positiva, a fecha de 30 de junio de 1996 art. 1(2). Mientras tanto, los Estados miembros deberían notificar a la Comisión la lista de Estados que se publicaría en el DOCE (art. 1(3)). El artículo 2 era la piedra angular de la propuesta preveía que los visados emitidos por algunos Estados
} 
mento. El texto final mostraba que el Consejo, no tenía intención de armonizar las políticas de visados en el marco del Tratado de la Comunidad Europea, en su lugar, la aproximación intergubernamental, ya sea Schengen o el Título VI, sería la utilizada.

Este Reglamento fue anulado por sentencia del Tribunal de Justicia de 10 de junio de 1997, sobre la base de que la propuesta había sido modificada. ${ }^{31}$ En su memorando, COM (93) 684 final, la Comisión mantenía que en razón de que el artículo 10o C TCE se encuentra entre las disposiciones del mercado interior. El Reglamento sobre visados ayudaría a la consecución de la libre circulación de personas. Esto sólo se podría llevar a cabo, según la Comisión, cuando el Consejo no sólo incluya los nombres de los terceros países cuyos nacionales deben estar provistos de visados (la denominada lista negativa), sino también elaborando una lista de Estados cuyos nacionales no requieren visado en ningún Estado miembro (lista positiva). El artículo $100 \mathrm{C}$ sólo hacía referencia a la lista negativa.

De acuerdo con el comentario realizado en el Informe sobre el Reglamento propuesto realizado en el marco del Comité de Libertades Civiles y Asuntos Internos, el miembro del Parlamento Europeo Froment - Meurice fue más lejos:

"Finalmente, pedimos la abolición de los visados nacionales. Esto es la más importante modificación. Sobre la base del hecho de que el artículo $100 \mathrm{C}$ incluye la armonización de la política de visados, pedimos la abolición de los visados nacionales al final de un período transitorio de 18 meses y que sean reemplazados por visados comunitarios. Estos visados seguirán siendo emitidos por las autoridades de los Estados miembros, pero dejarán de ser visados nacionales válidos en el Estado emisor únicamente, siendo visados comunitarios válidos en todos los Estados miembros de la Unión Europea”. ${ }^{2}$

Desde el punto de vista material, el artículo 4 presentaba un problema jurídico separado, este artículo prohíbe a los Estados Schengen permitir a los nacionales de terceros Estados residentes en otro Estado Schengen cruzar una frontera exterior sin un visado separado, y de forma similar también se impide en el Proyecto de Convención sobre el Cruce de Fronteras exteriores. Las derogaciones previstas en el artículo 4 de los requisitos para solicitar un visado no incluyen dichos motivos. Los términos "en particular" en este artículo son muy débiles para que incluya una exención tan amplia, y las referencias a actividades a realizar por Schengen tampoco prevé una derogación de ese tipo. Este conflicto no va a tener ningún

miembros deberían reconocerse por el resto de Estados miembros. Tres tipos de documentos se incluirían en la definición de visado a los efectos del Reglamento: los emitidos por tres meses (o para tres meses dentro de un período de seis meses), visados de tránsito para viajar por un Estado miembro; o zona de tránsito de un puerto o aeropuerto; y visados permitiendo a una persona volver al territorio de un Estado miembro en un período determinado. La propuesta de Convenio sobre el cruce de fronteras exteriores hubiese despojado de su sentido, el reconocimiento mutuo de visados del Reglamento, al disponer una lista de personas a las que se les rechazaría la entrada en las fronteras exteriores comunitarias, junto a una definición de visados más amplia, y requisitos comunes para conceder visados. El Parlamento Europeo fue muy crítico con la inacción de la Comisión y del Consejo en el ámbito de la libre circulación de personas, y propuso modificaciones fundamentales; ningún Estado podría incluirse en la lista negativa sí sus nacionales no requerían visados en todos los Estados miembros; los Estados miembros estaban obligados a adoptar la lista positiva a finales de 1995; la definición completa de visados; los requisitos para conceder un visado uniforme aplicable en todos los Estados miembros y el derecho de los nacionales de terceros Estados residentes en un Estado miembro para cruzar las fronteras exteriores de otro Estado miembro sin visado, pasaría del Convenio al Reglamento; y las personas a las que se negase un visado según el Reglamento tendrían un derecho de recurso ante las autoridades nacionales.

${ }^{31}$ Y no haberse realizado una nueva (2) consulta al Parlamento Europeo en el proceso legislativo. El Tribunal declaró que debería estar en vigor hasta que se adoptase una nueva medida.

${ }^{32}$ Debates en el P. E No. 3- 447 Reunión martes 19 abril 1994 p. 15 Informe A 3-0193/94. 
efecto jurídico, y se pasa por alto, ya que la Comisión no va a instigar procedimientos de infracción contra todos los Estados Schengen.

A lo que le siguió el Reglamento (CE) n. 574/9933 al igual que el primero, incluía la lista común de terceros países cuyos nacionales están sometidos a la obligación de visado. Los Estados miembros eran libres de imponer o no la obligación de visado a los nacionales de los terceros países que no figuraban en la lista común; es decir, junto a la lista negra y blanca, permanecía una lista gris.

En el primero de los Reglamentos, el número de Estados en la lista negativa se redujo de 126 a 101, eliminándose 28 países y añadiéndose 3 [sí un Estado se disuelve, los Estados que de él surjan también se situarán en la lista negativa, a menos que el Consejo determine lo contrario, art. 1(2)]; esto no aparecía en la propuesta de la Comisión. ${ }^{34}$

Los Estados que no aparecen en la lista final por intervención del Reino Unido;35 incluyen seis Estados de África meridional ${ }^{36}$ uno del Océano Índico, ${ }^{37}$ diez en el Caribe, ${ }^{38}$ y once en el Pacífico. ${ }^{39}$

Por regiones, sólo seis Estados del Continente americano aparecen en la lista negativa, ${ }^{40}$ todas las exrepúblicas socialistas (excepto los países bálticos) se encuentran en la lista, junto a otros seis Estados europeos. ${ }^{41}$ Se incluyen a todos los países asiáticos excluyéndose a cinco naciones con un alto índice económico. ${ }^{42}$ En el Oriente próximo, sólo queda excluida Israel.

La ausencia de la lista negativa sólo va a significar que al menos uno de los Estados miembros no es partidario de imponer visados a los nacionales de un Estados en particular. Mientras que no exista una lista positiva armonizada nada impide al resto de Estados miembros imponer visados a algún Estado que este fuera de la lista negativa.

En el ámbito comunitario, parecía inviable que se fuese a adoptar una lista positiva, y recaería por tanto, en el Tercer Pilar; ${ }^{43}$ así, el Consejo eliminó esta condición de adoptar una lista positiva en julio de 1996, y el Reglamento declaraba simplemente que "los Estados miembros deben determinar los requisitos de visados para nacionales de terceros Estados

${ }^{33}$ DOCE L 7218.31999 p.2 Adoptado previo dictamen del Parlamento Europeo de 10 de febrero de 1999 cumpliéndose así la formalidad que le faltaba por cumplir.

${ }^{34}$ Debido a la supresión de 28 países o territorios (casi todos de la Commonwealth) y la adición de tres: Perú, República federal de Yugoslavia y la ex república yugoslava de Macedonia.

${ }^{35}$ Los nacionales de la Commonwealth han conseguido retener, por ahora, el derecho de que sus familiares y amigos de la misma nacionalidad puedan entrar en el Reino Unido e Irlanda, exclusivamente sin necesidad de visado. Lo que evita gastos o el peligro de poder ver rechazada su solicitud.

${ }^{36}$ Sudáfrica, Lesotho, Swazilandia, Bostwana, Zimbabwe y Namibia. Zambia y la Comunidad de África Occidental siguen en la lista negativa; Kenia y Malawi nunca fue propuesta su inclusión.

37 Islas Seychelles, Mauricio y Maldivas siguen en la lista.

${ }^{38}$ Antigua y Barbados, Granada, Trinidad y Tobago, St. Lucia St. Kittis / Nevis y St. Vicente. El estado más extenso de la Commonwealth en el Caribe Jamaica nunca fue propuesto para su inclusión.

39 Micronesia, Islas Marshalls, Kiribati, Nauru, Islas Marianas del Sur, Islas Salomon, Tonga, Palou, Samoa Occidental, Tuvalu, y Vanuatu. Australia y Nueva Zelanda nunca fue propuesta su inclusión; Fiji - que ha dejado de ser un país de la Commonwealth, sigue en la lista.

$4^{\circ}$ Perú, Guyana, Surinam, Cuba, República Dominicana y Haití.

${ }^{41}$ Turquía, Albania, Bulgaria, Rumania, y los Estados de la antigua Yugoslavia.

42 Japón, Corea del Sur, Singapur, Malasia y Brunei.

${ }^{43}$ Respecto de la competencia para adoptar una lista positiva, tanto la Comisión como el Parlamento entienden que tienen competencia según el art. $100 \mathrm{C}$, aunque sólo se puede inferir, ya que la adopción de una lista positiva no se encuentra explícitamente, incluida entre "otros aspectos de la armonización que el Consejo deje al Tercer Pilar”. En mayor detalle, Valle Gálvez, A. “ La refundación de la libre circulación de personas, Tercer Pilar y Schengen: el espacio europeo de libertad, seguridad y justicia “ RDCE núm. 3 enero/junio 1998. 
que no estén en la lista (negativa)"al igual que "para apátridas y refugiados y personas con documentos de una entidad territorial o autoridad (...) en la lista común”. La Comisión debía realizar un informe del avance del proceso de armonización cinco años después de que el Reglamento entre en vigor y "si fuera necesario" proponer medidas "para conseguir (...) la armonización".

Además, el Preámbulo está lleno de frases que se refieren a la importancia del Tercer pilar, especialmente, para "otros aspectos de la armonización de la política de visados incluyendo las condiciones para la emisión de visados y reconocimiento mutuo".

Finalmente, el Reglamento se limitó a regular los visados emitidos por un período de tres meses, o para el tránsito por el territorio de un Estado miembro, exceptuando las vías aeroportuarias, y los visados de larga duración. Los Estados Schengen podrán adoptar explícitamente una lista negativa más amplia.

El Consejo permitió a los Estados miembros excluir a ciertos nacionales del visados "poseedores de pasaporte diplomático, miembros de servicios de rescate, (...) etc".

Ambos reglamentos presentan en su redacción más diferencias de estilo que de contenido, por lo que, respecto del resultado, puede sostenerse que reproducen prácticamente de forma idéntica lo esencial de su objeto de regulación. ${ }^{4}$

Su principal propósito radica en establecer una lista común, integrada por 100 Estados y un ente no reconocido como Estado por todos los Estados miembros, ${ }^{45}$ cuyos nacionales deberán estar provistos de un visado al cruzar las fronteras exteriores de los Estados miembros. ${ }^{46}$ Con ello se está contribuyendo a armonizar las políticas estatales en materia de visados, se garantiza la libre circulación de personas en el interior de la Comunidad y se lucha contra la inmigración ilegal.

Dicha contribución tan sólo puede calificarse como parcial, puesto que, por un lado, los Estados miembros pueden dispensar, desde un prisma general, la exigencia de visado a determinadas personas de conformidad con el Derecho internacional y con la práctica

\footnotetext{
${ }^{44}$ Entre las diferencias cabe destacar que si en el primero se aludía en algunos de sus considerandos al "marco del Título VI del Tratado de la Unión Europea" en el segundo se sustituye por la expresión "marco apropiado" En el cuarto considerando del primero se dice que "corresponde a los Estados miembros establecer" en el segundo se ha preferido señalar que "sería conveniente establecer". Se suprime el último de los considerandos del primer reglamento por sentido común y porque la realidad de las cosas lo ha dejado obsoleto. "Considerando que la información a que se refieren el apartado 4 del artículo 2 y el apartado 2 del artículo 4 deberá publicarse antes de que entren en vigor las restantes disposiciones, que, por consiguiente, el apartado 4 del artículo 2 y el apartado 2 del artículo 4 deberán entrar en aplicación un mes antes que las demás disposiciones del presente reglamento".

Lo cual ha influido sin duda en la supresión de la última parte del artículo 7: "excepto el apartado 4 del artículo 2 y el apartado 2 del artículo 4 que entrarán en vigor al día siguiente de su publicación”.

La alusión anterior del artículo 1 al "artículo $100 \mathrm{C}$ del Tratado" ahora se sustituye por la expresión "la disposición pertinente "y la del artículo 3" artículo $100 \mathrm{C}$ "por la actual "Tratado". Por otra parte, tres parecen ser las divergencias desde un prisma sustancial. Una, que el informe que se encarga realizar a la Comisión Europea sobre el estado de armonización de la política de los Estados miembros en materia de visados (según el noveno considerando y el artículo 3) tenía el plazo de 5 años tras la entrada en vigor del reglamento, y ahora, en la nueva norma, es "en el transcurso del primer semestre del año 2001". Dos, que el primer reglamento, salvo excepción, entró en vigor el sexto mes siguiente al de su publicación en el DOCE, mientras que el segundo reglamento entró en vigor in toto, al día siguiente al de su publicación en el DOCE. Tres, que en la lista común de Estado sí incluyen ahora la Ex- República Yugoslava de Macedonia, la República Federativa de Yugoslavia (Serbia y Montenegro), que en el primer reglamento formaban parte, junto a Taiwán, de los entes y autoridades territoriales no reconocidos como Estados por todos los Estados miembros.

${ }^{45} \mathrm{Su}$ inscripción en una u otra categoría no prejuzga en modo alguno su estatuto internacional....

${ }^{46}$ Según establece su artículo 1.
} 
consuetudinaria, ${ }^{47}$, por otro, pueden establecer excepciones con respecto a los nacionales de terceros Estados incluidos en la lista común, particularmente los miembros de la tripulación civil de los aviones y buques, el personal de vuelo y de acompañamiento de aviones en misiones de asistencia o salvamento y otras personas que presten socorro en caso de catástrofes y accidentes, así como para los titulares de pasaportes diplomáticos, pasaportes de servicio y otros pasaportes oficiales. ${ }^{48}$

Por otra parte, los Estados miembros tienen que decidir si el requisito de visado es exigible a los nacionales de terceros Estados que no figuren en la lista común, a los apátridas y a los refugiados, a quienes presenten un pasaporte o un documento de viaje expedido por un ente o autoridad territorial que no todos los Estados miembros reconozcan como Estados. ${ }^{49}$

Si el contraste entre lo que es común y las esferas particulares en las que los Estados miembros pueden tomar decisiones diversas a la regla general muestra que la flexibilidad es una de las notas características de esta normativa, no lo es menos el hecho de permitir llevar a cabo una mayor armonización que vaya más allá de la lista común..$^{\circ} \mathrm{Y}$ aunque parece respetar en un alto grado el principio de la autonomía decisoria estatal, introduce pautas y mecanismos de control sobre tales realizaciones en pos de una mayor coordinación, al tiempo que define el término "visado" en base a tres criterios cumulativos ${ }^{51}$ 633: el subjetivo- finalista, el temporal-espacial y el objetivo-espacial.

En efecto, con la obligación estatal de comunicar a la Comisión y comunicarse entre sí las medidas excepcionales que adopten los Estados respeto a refugiados, apátridas, o nacionales de terceros Estados no incluidos en la lista común se introduce un cierto grado de control que se consolida con la publicación en el DOCE, ${ }^{52}$ si bien es cierto que, por lógica, cualquier otra medida particular debería haber seguido el mismo o un parejo tratamiento.

Además, esta institución ha de elaborar un informe en el que evalúe el grado de armonización de la política de visados de los Estados miembros y proponer al Consejo de la Unión que adopte las medidas necesarias para conseguir la armonización por la que apuesta el Tratado de la Comunidad Europea. Por lo que respecta a la noción aludida y sus criterios, según el primero es una autorización expedida por un Estado miembro quien la exige para entrar en su territorio a determinadas personas. Gracias al segundo, aquellos que obtienen un visado no pueden permanecer en uno o más Estados miembros durante un tiempo que supere los tres meses. De acuerdo con el tercero, el visado da derecho a transitar por el territorio de cualquier Estado miembro, con la salvedad del tránsito por la zona internacional de los aeropuertos y de los traslados entre aeropuertos de un Estado miembro. ${ }^{53} \mathrm{Y}$ es que el régimen del tránsito aeroportuario se rige por visados ad hoc [véase, infra.]

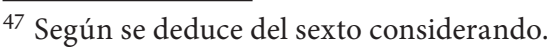

${ }^{48}$ Con base en el artículo 4. Sobre marinos véase, Reglamento (CE) n. 415/2003 del Consejo de 27 de febrero de 2003, sobre expedición de visados en fronteras, incluidos los marinos en tránsito. DOCE L 064/07/03/2003 p. ooo1-00o8. Normativa que sustituye a las Decisiones del Comité Schengen publicadas en el DOCE L 23922. 9. 2000 y en el Anexo XIV del Manual Común.

${ }^{49}$ Según el artículo 2.

50 Según lo preceptuado en el artículo 6.

${ }^{51}$ Conforme al artículo 5.

52 Artículo 2.4.

${ }^{53}$ Así se infiere del artículo 5.
} 


\subsection{VISADOS AEROPORTUARIOS}

\section{A) RÉGIMEN DE TRÁNSITO AEROPORTUARIO}

Las fronteras estatales aeroportuarias representan una importante vía de acceso de inmigrantes, ya que en ocasiones, se presentan solicitudes de entrada o entran de hecho en el territorio, para luego penetrar en el territorio de otro Estado miembro y allí establecerse, de forma ilegal.

Para luchar contra ese tipo de inmigración ilegal, se adoptó la acción común 197/96 JAI que en línea con el Convenio de Dublín, establece una excepción al anexo 9 del Convenio de Chicago relativo a la $\mathrm{OACI}^{54}$ que prescribe el libre tránsito por la zona internacional de los aeropuertos, ${ }^{55}$ esta acción común viene a imponer un visado de tránsito aeroportuario, según el cual: "la autorización a que estarán sujetos los nacionales de determinados terceros países (...) para transitar por la zona internacional de los aeropuertos”.

Corresponde la expedición de este tipo de visados a los servicios consultares de los Estados miembros, la principal obligación, que se establece es que, los Estados miembros exijan visados aeroportuarios a los nacionales de terceros Estados que se incluyan, en una lista común siempre y cuando no sean titulares de un visado de entrada o de tránsito en dicho Estado miembro.

\subsection{ACCIÓN COMÚN SOBRE ACUERDO DE TRÁNSITO AEROPORTUARIO}

El 4 de marzo de 1996, el Consejo adoptó, sobre una iniciativa francesa, ${ }^{56}$ una acción común en el marco del artículo K. 3 del TUE sobre acuerdos de tránsito aeroportuario. Aunque la acción común presenta la obligación de emitir un visado de tránsito aeroportuario, el propósito de la medida que se presenta en el Preámbulo muestra que es una medida respecto de la inmigración ilegal.

"Dado que las políticas de armonización de los Estados miembros en este ámbito están en conformidad con los objetivos del Tratado de seguridad y control de la inmigración ilegal y contribuir a la armonización de las condiciones de competencia entre líneas aéreas y aeropuertos en los Estados miembros"

Además, el Preámbulo de forma explícita afirma que la acción común no "concierne los visados requeridos al cruzar las fronteras externas de los Estados miembros y por lo tanto no queda cubierta por el artículo 100 C (1) del Tratado"

\footnotetext{
54 Organización de la Aviación Civil Internacional organismo especializado de Naciones Unidas. Los estándares internacionales de transporte aéreo se han modificado para que encajasen mejor con esta estrategia de control. Véase, VEDSTED-HANSEN, J. "Amendments to the ICAO Standards on Carriers ' Liability to Immigration control" KJAERM, M. (ed) The effect of Carriers Sanctions on the Asylum System (1991) p. 23.

55 No es esta la única incompatibilidad con el Convenio de Chicago de 7 de diciembre de 1944, respecto a las sanciones a los transportistas, el Anexo 9 prevé explícitamente la no imposición de sanciones a los transportistas en caso de que los pasajeros no sean admitidos en el Estado de destino, exceptuando aquellos supuestos en los que exista negligencia manifiesta. Véase CRUZ, A. "Compatibility of carriers sanctions in four Community States with international civil aviation and human rights obligations” en MEIJERS. H. et al: Schengen - Internalisation of central chapters of the Law on aliens, refugees, privacy, security and the police Kluwer Law and Taxation 1991 pp. 37-56.

${ }^{56}$ Lanzada por la Presidencia francesa del Consejo en febrero de 1995 que llevó a su adopción — sin participación de la Comisión-.
} 
Estos visados seguirán siendo emitidos por las autoridades de los Estados miembros, pero dejarán de ser visados nacionales válidos en el Estado emisor únicamente, siendo visados comunitarios válidos en todos los Estados miembros de la Unión Europea. ${ }^{57}$

Por lo tanto, el P. E mantenía una visión amplia de que los requisitos para conceder un visado, el reconocimiento mutuo y la competencia para adoptar una lista positiva recaían bajo el artículo 100 C TCE. Por su parte, el Consejo mantenía una visión más estrecha del artículo 100 C TCE que incluía todos estos aspectos, con la excepción del establecimiento de una lista negativa, entre los aspectos de la armonización bajo el Tercer Pilar.

Sin embargo, el P.E y el Consejo se mostraron de acuerdo en que por razones de coherencia el reconocimiento mutuo de visados y el establecimiento de una lista positiva debía considerarse conjuntamente ya sea según el artículo $100 \mathrm{C}$, o en el Tercer Pilar. Pero como PEERS apuntaba;

"parece infantil buscar una división coherente de competencias en la oscuridad de los pilares de la Unión”. Además, el contenido del artículo 100 C y K. 1 no vierten luz en el asunto, desde el momento en que una lista positiva podría ser también parte de "la determinación de los terceros países cuyos nacionales deben encontrarse en poder de un visado" artículo $100 \mathrm{C}$, como una condición de entrada y movimiento de los nacionales de terceros países en el territorio de los Estados miembros (art. K. 13 (a))

El Tribunal se limita a interpretar el artículo 100 C según su práctica considerando "el espíritu general y enunciado del mismo" al igual que "los sistemas y objetivos del Tratado"

El Consejo de la Unión claramente desea limitar el contenido del reglamento de visado, porque su base jurídica lo convertiría en una medida comunitaria obligatoria y dentro de la Jurisdicción del Tribunal. El establecimiento de una lista positiva se considera un ámbito para la cooperación entre los Estados miembros bajo el Título VI TUE. La Comisión apoyada por el Parlamento Europeo inició una acción de anulación de esta acción común ante el TJCE, declarando que debía haberse basado en el artículo 10o C TCE; el Tribunal afirmó que tenía competencia para anular dicho acto "si se mostraba que debía estar basado en el artículo $100 \mathrm{C}$ del Tratado CE" 58 aunque, finalmente, no lo hizo. Esta facultad deriva del artículo M del TUE que afirma que nada en el TUE puede afectar a los Tratados constitutivos de las Comunidades.

En la opinión mayoritaria, el Tribunal podía declarar que un acto como la acción común debía estar basado en el artículo 100 C TCE. Sin embargo, nunca podría anular una acción común. No existe un razonamiento que permita un juicio en esta dirección.

Otro aspecto importante es el relativo a la naturaleza obligatoria de una acción común, se deriva del hecho de que el Tribunal se muestre partidario a su anulación, indica que estamos ante un instrumento vinculante.

El antiguo artículo 173 puede ser utilizado para considerar actos sui generis previendo que tienen naturaleza vinculante o producen efectos legales.

Sin embargo, en este asunto, el Tribunal carece de competencias para revisar el acto, ya que la Comisión no pide la revisión de la acción común, sino solo una declaración de que

\footnotetext{
${ }^{57}$ Debates en el P. E No. 3-447 Reunión Martes 19 de abril 1994 p. 15 Informe A3 - 0193/94 Los diez países eran: Afganistán, Etiopia, Ghana, Irak, Irán, Nigeria, Somalia, Sri Lanka, (ex) Zaire.

${ }^{58}$ Asunto C- 170/96 Comisión c. Consejo. Sentencia de 12 de mayo 1998 p. 17. Recueil 1998 I-2763.
} 
"a la luz de los objetivos, la acción adoptada por el Consejo recae en el ámbito del artículo 100 C".

La forma de la acción común adoptada puede seguir siendo una acción común, lo que deja abierta la cuestión de su naturaleza vinculante o no. El hecho de que los negociadores de Ámsterdam no aprovecharan la oportunidad para decidir sobre la naturaleza obligatoria de la Acción común fue un error mayúsculo; ya que será necesario realizar una aproximación caso por caso.

Cuando la acción común se transfiera a su nueva base jurídica se convertirá en legislación secundaria del Título IV TCE, sobre la que el Tribunal podrá ser cuestionado a adoptar "un dictamen sobre la cuestión de la interpretación (art. 68 p. 3 TCE)”. Es de esperar que llegado el momento, el Tribunal declarará su naturaleza vinculante, KLABBERS, en un artículo sobre acuerdos informales llegó a la conclusión de que el Tribunal:

"ha favorecido de forma reiterada el contenido sobre la forma, una aptitud que [...] sólo puede explicarse metodológicamente empezando desde la presunción de que el acuerdo crea derechos y obligaciones legalmente vinculantes, a menos que lo contrario pueda ser demostrado de forma clara". 59

Finalmente, resulta claro que la transferencia de una base intergubernamental a una base comunitaria no puede volver el acto de forma automática en un acto comunitario. Algunos elementos de la esfera de cooperación siguen presentes tales como la arbitrariedad de su fuerza vinculante.

Debido al hecho de que el Título IV no se aplique al Reino Unido, Irlanda y Dinamarca, las adaptaciones de una acción común después de la entrada en vigor del Tratado de Ámsterdam van a reducir territorialmente el funcionamiento de la acción común. Esto resalta la conclusión de que la transferencia de una medida K. 3 al Primer pilar no es una transferencia de la esfera Intergubernamental a la Comunitaria, sino simplemente, una transferencia a una esfera en un lugar intermedio entre el modelo clásico comunitario y la cooperación intergubernamental (véase, supra).

\section{MODELO UNIFORME DE VISADOS ${ }^{60}$}

El visado uniforme, con validez para el territorio de todos los Estados parte, constituye probablemente el eje central sobre el que gira esta política común de visados.

\footnotetext{
${ }^{59}$ KLABBERS, "Informal agreements before the European Court of Justice" CML Rev. (1994) pp. 997-1023. En Schengen, Véase, Parte I del Anexo 3 de la Instrucción consular común y de la Parte I del Anexo 5 a) del Manual Común, referentes a los nacionales de terceros países sujetos a la obligación del visado aeroportuario. Véase, la Propuesta de Reglamento sobre un visado de tránsito aeroportuario que debía haber sido adoptado en abril de 2001. Comisión de las Comunidades Europeas Bruselas 22.5.2003 COM (2003) 291 final. Comunicación de la Comisión Europea al Consejo y al Parlamento Europeo. Actualización Semestral del marcador para supervisar el progreso en la Creación de un Espacio de "Libertad, Seguridad y Justicia" en la Unión Europea. Primer semestre 2003. Relacionado con los visados aeroportuarios, cabe destacar la medida adoptada en el tráfico ferroviario para solucionar la peculiar situación del enclave ruso de Kaliningrado. Reglamento (CE) n. 694/2003 del Consejo, de 14 de abril de 2003, sobre los modelos uniformes de documentos de tránsito facilitado (FTD) y de documentos de tránsito ferroviario facilitado (FRTD) establecidos por el Reglamento (CE) n.693/2003 Diario Oficial n. L 099 de 17/04/2003 p. 0015 -0021.

${ }^{60}$ Es de destacar como primer paso, la RECOMENDACIÓN DEL CONSEJO RELATIVA A LA COOPERACIÓN CONSULAR EN MATERIA DE VISADOS - de 4 de marzo de 1996 DOCE C 80 18.03.96.
} 
En el plano Schengen, su regulación en el Convenio de Aplicación de Schengen ${ }^{61}$ ha tenido sin duda una incidencia práctica indiscutible.

El Estado responsable de su expedición (el de destino principal o el de primera entrada), junto con sus autoridades (fundamentalmente diplomáticas y consulares), ${ }^{62}$ la prohibición de estamparse en documento de viaje caducado, ${ }^{63}$ el mutuo reconocimiento estatal de sus respectivos visados durante el período transitorio hasta la instauración del mencionado visado, ${ }^{64}$ y las importantes competencias que se reservan al Comité Ejecutivo en esta materia $^{65}$ conforman los principales contenidos normativos de sus disposiciones. ${ }^{66}$

Al no disponerse de Convenio que regule el cruce de las fronteras exteriores ni de un manual comunitario para la expedición de los visados, ni siquiera para los de modelo uniforme, la cooperación consular local en el marco de la UE es muy incipiente y somera. Es por ello que el texto adopta la fórmula más flexible de una recomendación, lejos por tanto de otras fórmulas comunitarias de contenido más imperante en el marco del Tercer pilar: posición común, acción común, resolución, Convenio, etc. El contenido de la Recomendación, a diferencia de lo que sucede con Schengen, marca apenas unas líneas de actuación tendentes a la no distorsión de las políticas de cada Estado. Los servicios consulares comunitarios intercambiarán información sobre los criterios de tramitación de visados y sobre los riesgos para la seguridad, orden público, e inmigración clandestina. Celebrarán reuniones periódicas, intercambiarán visitas de los funcionarios encargados de tramitar los visados, elaborarán - cuando se les pida - informes conjuntos; podrían adoptar medidas conjuntas para detectar solicitudes simultáneas o en cadena y se ayudarán para verificar la buena fe y referencias sobre los solicitantes debiendo para ello tomar en consideración las normas pertinentes a la protección de datos. Véase. Decisión del Consejo, de 27 de marzo de 2000 relativa a la mejora del intercambio de información para combatir los documentos de viaje falsos.

${ }^{61}$ España añadió una declaración que se reflejó en el Acta Final (acuerdo de adhesión de España) relativa a las ciudades de Ceuta y Melilla. En la que reafirmó el mantenimiento de una serie de controles sobre viajeros y mercancías provenientes de estas ciudades, así como la exención de visado en materia de pequeño tráfico fronterizo entre éstas y las provincias marroquíes de Tetuán y Nador y el mantenimiento de un visado limitado múltiple para los no residentes en esas provincias marroquíes que deseen entrar en Ceuta y Melilla. Véase texto, en CARRERA HERNÁNDEZ, F.J. /NAVARRO BAUTISTA, N. El Espacio de libertad, seguridad y justicia en la Unión Europea. Textos fundamentales. Tecnos. 1999.

${ }^{62}$ Artículo 12 Convenio Aplicación de Schengen.

63 Artículo 13 Convenio Aplicación de Schengen.

${ }^{64}$ Según el contenido del artículo 10.2 del Convenio de Aplicación de Schengen.

${ }^{65}$ Véase el artículo 17 del Convenio de Aplicación de Schengen.

${ }^{66}$ La diferencia que en él se vislumbra entre visado de viaje y visado de tránsito, según sirva para una o varias entradas sin que la duración de una estancia ininterrumpida o la duración total de las estancias sucesivas pueda superar los tres meses por semestre, contados a partir de la primera entrada, o que permita a su titular transitar una, dos o excepcionalmente varias veces por los territorios de los Estados signatarios para dirigirse al de un tercer país siempre que la duración del tránsito pueda ser superior a cinco días [esto no impide que, durante el semestre de que se trate, un país expida en caso de necesidad un nuevo visado válido únicamente a su territorio. Artículo 11 Convenio de Aplicación de Schengen] ha quedado reducida a una cuestión meramente formal, porque el reglamento n. 1683/95 que el Consejo adoptó el 26 de mayo de 1995, no contempla expresamente esa diferenciación. 
En el plano comunitario, la Comisión presentó un modelo de visado único para los Estados miembros ${ }^{67}$ que el Consejo adoptó en forma de Reglamento, ${ }^{68}$ considerando que la introducción de un modelo uniforme representa un paso importante hacia la armonización de la política en materia de visados, ${ }^{69}$ y cuyo artículo 5 entiende a efectos del presente Reglamento, por "visado".

"una autorización administrativa concedida o una decisión tomada por un Estado miembro exigida para entrar a en su territorio: - una estancia prevista en dicho Estado miembro o en varios Estados miembros, por un período cuya duración total no sea superior a tres meses; - el tránsito a través del territorio o de una zona de tránsito de aeropuerto de dicho Estado miembro, o de varios Estados miembros".70

Apareciendo aquí los mismos elementos que conforman el concepto de visado en el reglamento n. 2317/95, salvando las excepciones de tránsito de aquel, diferencias que son difíciles de comprender máxime si se piensa que estamos ante dos normas comunitarias de idéntica naturaleza, el mismo fundamento jurídico, y adoptadas en el tiempo con una separación aproximada de tres meses.

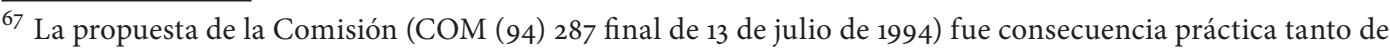
los debates suscitados gracias a la Comunicación de febrero de 1994 sobre las políticas de inmigración y el derecho de asilo (COM (94) 23 final de 23 de febrero de 1994) cuanto del contenido del apartado 3 del artículo 100 C del TUE como del artículo 1o del Convenio de aplicación de Schengen. Con ella se pretendió contribuir al logro de la libre circulación de personas dentro del mercado interior, de conformidad con lo previsto en el artículo $7 \mathrm{~A}$, pero al, propio tiempo respetando los derechos fundamentales de los ciudadanos de conformidad con el apartado 2 del artículo $\mathrm{F}$ del Tratado de la Unión, tales como la protección de la vida privada o la protección de los datos personales. Por ello, aparte de establecerse a lo largo de sus siete artículos una serie de características y especificaciones técnicas para evitar su imitación o falsificación [véase la Recomendación 98/C del Consejo, de 28 de mayo de 1998, sobre equipo para detección de falsificaciones en los puntos de entrada en la Unión Europea DOCE C 189 de 17.6.98 ] - La Comisión ya ha ejercido esta competencia una vez, al adoptar una Decisión sobre especificaciones complementarias técnicas del modelo uniforme de visado. Decisión 2/96 sin publicar 7-02-1996 y el 27 de 12 de 2000. Decisión COM (2000) 4332 sin publicar. - que han de completarse con decisiones tomadas de conformidad con el artículo 191, se determina que han de protegerse los datos personales e incluso que el titular de un visado tiene derecho a ser informado del contenido de los datos personales legibles electrónicamente y a pedir, en su caso, a las autoridades de expedición la rectificación de dichos datos. Por lo demás se restringe el acceso a este tipo de información confidencial a las personas debidamente autorizadas por los Estados miembros y por las instituciones comunitarias, al tiempo que este modelo se concibe para poder servir para todo tipo de visados: entrada, de tránsito, de reentrada, de corta o de larga duración.

${ }^{68}$ COM (94) 28713 de julio de 1994 Reglamento del Consejo 1683/95 DOCE L 164/1.En vigor desde el 24 de febrero de 2002, adopción de las especificaciones necesarias para su aplicación 3.6.2002.

${ }^{69}$ Representa una de las piezas esenciales de la política comunitaria sobre visados y ha sido una de las normas vanguardistas del actual espacio europeo de libertad, seguridad y justicia. A través de él se ha hecho realidad los principios de universalidad en la utilización a nivel comunitario y de la protección contra imitaciones y falsificaciones a escala de la Unión Europea.

${ }^{70}$ Véase; Decisión 94/795 JAI del Consejo de 30 de noviembre de 1994 sobre una acción común adoptada por el Consejo en virtud de la letra b) del punto 2 del artículo K. 3 del Tratado de la UE relativa a las facilidades de desplazamiento para los escolares de terceros países que residan en un Estado miembro; acción común 96/197 JAI de 4 de marzo de 1996 adoptada por el Consejo sobre la base del artículo K. 3 del TUE, sobre el régimen del tránsito aeroportuario; artículos 9 y sigss. del Convenio de Aplicación de Schengen; Acervo Schengen Decisión del Comité Ejecutivo de 26 de abril de 1994 DOL 239 22.09.2000; y Acervo Schengen Decisión del Comité Ejecutivo de 22 de diciembre de 1994 DOL 239 22.09.200o.
} 
Las obligaciones de mayor calado de los Estados miembros son de carácter administrativo, pues se obligan a designar un organismo único encargado de imprimir los visados, y de comunicación, habida cuenta de que han de comunicarse entre sí y a la Comisión Europea el organismo designado. ${ }^{71}$ También pueden utilizar este modelo de visado para otro tipo de autorización siempre y cuando incorporen diferencias visibles a simple vista que impida cualquier tipo de confusión con el visado uniforme. ${ }^{72}$

Finalmente, es destacable la garantía del respeto de los datos personales de aquellos que obtienen un visado $;^{73}$ y ello no sólo por la necesidad de respetar el Derecho interno estatal y el Derecho comunitario que inciden en esta materia, sino también porque se reconoce expresamente el derecho a comprobar los datos personales que constan en su visado y, en su caso, que sean suprimidos o rectificados. Todo lo estipulado en el reglamento entró en vigor en agosto de 1995, con la salvedad de la etiqueta adhesiva a utilizar por los Estados miembros, que representa verdaderamente, el modelo uniforme de visado que está vigente desde agosto de $1996 .^{74}$

La versión definitiva de Reglamento del Consejo75 contiene dos modificaciones: (1) El artículo 2 se sustituye por:

Artículo 2 - Para el modelo uniforme de visado, se establecerán de conformidad con el procedimiento al que se refiere el apartado 2 del artículo 6, especificaciones técnicas adicionales referidas a:

(a) nuevos requisitos de seguridad, incluidas normas reforzadas contra imitaciones y falsificaciones.

(b) condiciones de custodia para evitar robos

(c) condiciones de expedición del modelo uniforme de visado

(d) otras condiciones necesarias para el establecimiento del modelo uniforme de visado.

(2) El Artículo 6 se sustituye por:

Artículo 6 - (1) La Comisión estará asistida por un Comité compuesto por los representantes de los Estados miembros y presidido por un representante de la Comisión

(2) Siempre que se haga referencia a este apartado, se aplicará el procedimiento de reglamentación establecido en el artículo 5 de la Decisión 1999/468/CEE, en relación con su artículo 7.

(3) El plazo previsto en el apartado 6 del artículo 5 será de un mes.

\footnotetext{
${ }^{71}$ Artículo 3.

${ }^{72}$ Véase el Preámbulo y el artículo 7.

73 Artículo 4.

74 Artículo 8.

75 Reglamento del Consejo- (CE) n. 334/2002 de 15 de febrero de 2002 por el que se modifica el Reglamento 1683/95 por el que se establece un modelo uniforme de visado. DO L 53/7 23. 2. 2002. Estas modificaciones son principalmente técnicas relacionadas a cuestiones de seguridad como consecuencia de nuevos adelantos tecnológicos.
} 
Las principales innovaciones son las de ampliar el mandato del comité establecido por el artículo 6 del Reglamento sobre el modelo uniforme de visado de conformidad con el procedimiento establecido en el artículo 5 de la Decisión 1999/468/CE en relación con su artículo 7. Este Comité es responsable de todas las medidas de ejecución, especialmente en relación con las normas comunes relativas a expedición del impreso.

Además de las especificaciones técnicas acordadas, resulta necesario fijar condiciones adicionales, tales como las relacionadas con la custodia de las etiquetas adhesivas de visado en blanco.

La Comisión considera que es importante establecer un modelo uniforme de impreso para la colocación del visado.

El reglamento se basa en el trabajo ya realizado en los grupos de trabajo del Consejo. El modelo debe consistir en un impreso que satisfaga criterios de seguridad de alto nivel para evitar simulaciones y falsificaciones. Debe constituir un soporte del modelo uniforme de visado de conformidad con el Reglamento CE n. 1685/95 que debe ponerse, en casos excepcionales, cuando el pasaporte no se reconoce por el Estado miembro que expide el visado y no debe sustituir a los documentos de viaje.

La Comisión considera que en una situación en la que los documentos de viaje existen pero no reconocidos formalmente por un Estado miembro, el objetivo del impreso estándar es proporcionar un soporte alternativo para que, no obstante, se pueda expedir y aplicar el modelo uniforme de conformidad con las disposiciones del Reglamento 1683/95.

En estas circunstancias, el impreso forma parte integrante de la aplicación del propio modelo uniforme y debería por lo tanto, basarse en el inciso (iii) de la letra b) del apartado 2) del artículo 62. La base jurídica del Reglamento sobre modelo uniforme para la colocación del visado es la misma que la que se aplica a la modificación del Reglamento 1683/95, esto es el inciso (iii) de la letra b) del apartado 2 del artículo 62 del Tratado CE ya que el modelo uniforme para la colocación del visado uniforme forma parte integrante del visado. La base jurídica respecto del modelo uniforme para la colocación del visado y modificación del Reglamento 1683/95 caen dentro del ámbito del Título IV del Tratado, de manera que entre en juego la solución variable, tal y como se establece en los Protocolos sobre la posición del REINO UNIDO, IRLANDA Y DINAMARCA. Tanto NORUEGA como ISLANDIA según el artículo 6 del Protocolo de Schengen, firmaron un acuerdo con el Consejo sobre la asociación de estos dos Estados a la ejecución, aplicación y desarrollo del acervo Schengen, en cuyo anexo B figura el Reglamento del Consejo 1683/95. Por tanto, el asunto deberá abordarse en el Comité Mixto con ocasión de "explicar los problemas que observen en relación con 'la medida y' para expresarse en relación con toda cuestión relativa al establecimiento de disposiciones que afecten a dichos países o a su aplicación”. Noruega e Islandia ejecutarán y aplicarán la modificación del Reglamento. El mismo procedimiento debería aplicarse respecto de la propuesta de Reglamento sobre un modelo uniforme para la colocación del visado que la Comisión lo considera como parte integrante del modelo uniforme de visado.

\subsection{COOPERACIÓN REFORZADA EN VISADOS SCHENGEN}

En el ámbito de la cooperación reforzada, los Estados Schengen tienen permitido adoptar una lista negativa más amplia; la legalidad de tal cooperación respecto del derecho comunitario, se confirma en ambos reglamentos, que declaraban que sus disposiciones no cons- 
tituían un obstáculo para una mayor armonización entre Estados miembros cuyo alcance superara el de la lista común.

El Acervo Schengen se extiende a los visados de entrada de tres meses; los visados de tránsito sólo para un término de 5 días; los visados de mayor duración sólo tendrán aplicación en el territorio de la Parte contratante que la concede.

Los visados de corta duración serán concedidos por el Estado que sea destino principal, y sí este no pudiera determinarse, al puesto consular o diplomático de la Parte contratante de primera entrada (art. 12.2 $)^{76}$

Una política conjunta de visados supone la agrupación en una lista conjunta de los países terceros cuyos nacionales necesitarán visado, que al momento de la firma del Convenio comprendían una lista negra, de 129 Estados, que según el artículo 9 párrafo 2 sólo podría ser modificada de común acuerdo. ${ }^{77}$

Esta mayor armonización de los Estados Schengen que se viene haciendo de forma progresiva y que en el momento de la integración de Schengen en el sistema de la Unión Europea es el siguiente:

a) Una lista de 32 terceros países que no figuraban en la lista del Reglamento (CE) n. 574/99 y cuyos nacionales están sometidos a la obligación de visado en todos los Estados Schengen. b) Una lista de 44 terceros países cuyos nacionales están exentos de visado en todos los Estados Schengen. ${ }^{78}$

Este acervo de Schengen forma parte integrante del Derecho comunitario, desde la entrada en vigor del Tratado de Ámsterdam y sigue aplicándose entre los Estados de Schengen. En lo referente a la especial posición del Reino Unido e Irlanda, que en virtud del Protocolo de Schengen pueden solicitar en cualquier momento la participación en la totalidad o parte del acervo Schengen, situación que se ha producido con la presentación de cartas del Reino Unido al Presidente del Consejo, ${ }^{79}$ no se refiere a asuntos relacionados con los visados.

En la lista blanca sólo se encuentran 26 Estados que no requieren sus nacionales visados de los Estados Schengen; existiendo también una lista gris que resulta más problemática, que requieren un visado para determinados Estados miembros, y no para otros; número de Estados que asciende a 23. Corresponderá al Comité Ejecutivo del Convenio bien reducir este número o eliminar el grupo, para encuadrarlo bien en la lista blanca o en la negra.

La política de visados común del artículo 9. 1, es algo transitorio, desde el momento en que se vincula a la existencia de un visado uniforme válido para el territorio de todos los Estados contratantes (art. 10. párrafo 1); válido para tres meses, emitido por el Estado de

\footnotetext{
${ }^{76}$ Art. 12. 2 La Parte contratante competente para expedir dicho visado será, en principio, la del destino principal y, si éste no puede determinarse, la expedición del visado incumbirá en principio al puesto diplomático o consular de la Parte contratante de primera entrada.

77 Art. 9. 2 Por lo que respecta a terceros Estados cuyos nacionales estén sujetos a un régimen de visados común a todas las Partes contratantes en el momento de la firma del presente Convenio o después de la misma, dicho régimen de visados sólo podrá modificarse de común acuerdo entre todas las Partes contratantes. Una Parte contratante podrá hacer excepciones al régimen común de visados respecto de un tercer país, por motivos imperiosos de política nacional que exijan una decisión urgente. Deberá consultar previamente a las demás Partes contratantes y tener en cuenta los intereses de éstas al adoptar su decisión, así como las consecuencias de las mismas.

${ }^{78}$ No había equivalente en el marco del Reglamento (CE) n. 574/99 que no incluía esta lista.

79 Cartas de 20.5.1999, 9.7. 1999 y 6.10. 1999.
} 
destino principal. Como medida transitoria hasta la creación del visado uniforme, las Partes contratantes reconocerán sus visados nacionales respectivos (artículo 10. 2). ${ }^{80}$

Finalmente, en los artículos 12 a 17 se regulan particularidades técnicas.

La exclusión del reconocimiento mutuo y de una lista positiva en el Derecho comunitario, la necesidad de una armonización adicional, y el bloqueo de la Convención de las Fronteras Exteriores debe considerarse en relación con el avance del sistema Schengen, ${ }^{81}$ cuyo capítulo tercero hace referencia al sistema de visados.

Como hemos visto, en el Tratado de Maastricht, ${ }^{82}$ la política de Inmigración y Asilo del Consejo y de la Comisión ha estado caracterizada por una cierta reserva que se deriva ante todo de la escasa disposición de los Estados miembros para limitar su soberanía en este ámbito. A ello se añadía la falta de claridad debido a que el artículo $100 \mathrm{C}$ del Tratado de la Unión Europea de Maastricht no mencionara expresamente las competencias, ${ }^{83}$ mien-

\footnotetext{
${ }^{80}$ Que queda regulada por el Reglamento n. 1683/95 de 29 de mayo de 1995 DOCE. L 164 14.7.95 Modificado por el Reglamento (CE) n. 334/2002 del Consejo de 18 de febrero de 2002 por el que se establece un modelo uniforme de visado DOCE L. 53 23.02.2002 p. 2.

${ }^{81}$ En varias disposiciones se prevé la adopción de normas de ejecución por el Comité Ejecutivo establecido por los acuerdos de Schengen. Comité al que sustituye el Consejo. Como establece el artículo 1 del Protocolo sobre el Acervo Schengen, la cooperación en este contexto debe llevarse a cabo en el marco institucional y jurídico de la Unión Europea y respetando las disposiciones pertinentes del Tratado de la Unión Europea y de la Comunidad Europea. Por ello se adoptan estos Reglamentos con el fi n de establecer en un acto comunitario el procedimiento de adopción de tales decisiones de ejecución. Véanse, los avances de Schengen: 1) Reglamento (CEE) n. 789/2001 del Consejo de 24 de abril de 2001, por la que el Consejo se reserva competencias de ejecución en relación con determinadas disposiciones detalladas y procedimientos prácticos de examen de solicitudes de visado. DOCE L 116-26.4.2001 Modificado por 2004/927/CE: Decisión del Consejo, de 22 de diciembre de 2004, por la que determinados ámbitos cubiertos por el Título IV de la Tercera parte del Tratado constitutivo de la Comunidad Europea se regirán por el procedimiento previsto en el artículo 251 de dicho Tratado DO L 396 de 31.12.2004, p. 45/46.
}

2) Reglamento (CE) n. 790/2001 del Consejo de 24 de abril de 2001, por el que el Consejo se reserva competencias de ejecución en relación con determinadas normas de desarrollo y procedimientos prácticos para la realización de controles y vigilancia en las fronteras. DOCE L 116-26.4.2001. Modificado por Reglamento (CE) n. 562/2006 del Parlamento y del Consejo de 15 de marzo de 2006 por el que se establece un Código comunitario de normas para el cruce de personas por las fronteras. DOCE L 105/1 13.4.2006.

${ }^{82}$ Mangas Martin, A. El Tratado de la Unión Europea. Gaceta Jurídica de la Unión Europea. 2 vols. 1992.

${ }^{83}$ El contenido del artículo poco utilizado en la práctica preveía Véase, supra nota al píe núm. 505 "1. El Consejo, por unanimidad, a propuesta de la Comisión y previa consulta al Parlamento Europeo, determinará los terceros países cuyos nacionales deban estar provistos de un visado al cruzar las fronteras exteriores de los Estados miembros. 2. No obstante, si se diera una situación de emergencia en un tercer país, que supusiera un riesgo de súbita afluencia de nacionales de dicho país a la Comunidad, el Consejo podrá, por mayoría cualificada, sobre la base de una recomendación de la Comisión, establecer, durante un período de que no supere los seis meses, el requisito de visado para los nacionales de dicho país. El requisito de visado establecido con arreglo a este apartado podrá ampliarse conforme al procedimiento a que se refiere el apartado 1. 3 . A partir del 1 de enero de 1996, el Consejo deberá pronunciarse por mayoría cualificada sobre las decisiones a que se refiere el apartado 1 . El Consejo deberá adoptar, antes de dicha fecha, por mayoría cualificada, a propuesta de la Comisión y previa consulta al Parlamento Europeo, las medidas relativas a un modelo uniforme de visado. 4. En los ámbitos contemplados en el presente artículo, la Comisión procederá a tramitar toda petición formulada por un Estado miembro en el sentido de que aquélla presente una propuesta al Consejo. 5. El presente artículo no afectará al ejercicio de las responsabilidades que competen a los Estados miembros para el mantenimiento del orden público y la salvaguardia de la seguridad interior. 6. Las disposiciones del presente artículo se aplicarán a otros asuntos, si así se decidiera en virtud del artículo K. 9 de las disposiciones del Tratado de la Unión Europea relativas a la cooperación en los ámbitos de la justicia y de los asuntos de interior, sin perjuicio de las condiciones de votación determinadas al mismo tiempo. 7. Las disposiciones de los convenios vigentes entre los Estados miembros relativas a materias contempladas en el presente artículo permanecerán en vigor mientras no se sustituya su contenido por directivas o medidas adoptadas de 
tras que el sistema comunitario e incluso la convención intergubernamental sobre Cruce de Fronteras languidecían, nos encontrábamos ante la expansión del sistema intergubernamental Schengenland, siendo necesario esperar hasta la entrada en vigor del Tratado de Ámsterdam con las nuevas disposiciones para albergar nuevas esperanzas. El problema principal es que el requerir visados a nacionales de terceros países no tiene mucho sentido y puede degenerar en una pura formalidad mientras que no exista un criterio común para conceder visados. De ahí que los Estados miembros entiendan que difícilmente vayan a poder reconocer un visado emitido por otro Estado miembro, incluso si se alcanza un acuerdo, su efectividad será difícil, más aún con la ampliación a nuevos Estados miembros.

Otro ejemplo de medida de cooperación reforzada ${ }^{84}$ aunque no strictu sensu, es la dirigida a facilitar la circulación con visados de larga duración, así, el Reglamento (CE) 1091/2001 del Consejo de 28 de mayo de 2001 relativo a la libre circulación con visados para estancias de larga duración. ${ }^{85}$

Este Reglamento reemplaza el artículo 18 del Convenio Aplicación del Acuerdo de Schengen por un nuevo texto que permitirá a los titulares de un visado nacional para un estancia de larga duración expedido por un Estado miembro desplazarse hacia otros Estados miembros durante un período de tres meses a contar desde la fecha inicial de validez siempre y cuando en la expedición del visado se hayan respetado las condiciones y criterios pertinentes.

Las disposiciones del presente Reglamento no serán de aplicación, ni a Dinamarca, ni al Reino Unido, ni a Irlanda, ya que estos Estados no se encuentran en Schengen.

Finalmente, y como apunta el Profesor CHUECA SANCHO, A."resulta de extraordinaria importancia para los movimientos migratorios tanto el Manual común como la Instrucción consular, y un conocimiento de estos textos va a contribuir a una mejor defensa de los extranjeros que desean venir a la Unión Europea cuyos derechos humanos no van a verse violados cualquiera que sea su status migratorio, además se evitará la enorme discrecionalidad de la que disfrutan los agentes diplomáticos y consulares. ${ }^{86}$

Ante la denegación del visado se abre la vía de un recurso bien ante la Oficina consular denegatoria y por ultimo ante los Tribunales nacionales que en su caso deben aplicar la normativa armonizada por el Tribunal de Justicia de la Unión Europea, en definitiva, un proceso largo que contradice el espíritu común de la emisión del visado.

conformidad con el presente artículo". Texto. Tratado de la Unión Europea y Tratados Constitutivos de las Comunidades Europeas, Tecnos 2003. 9 ed. MANGAS MARTíN, A.

${ }^{84}$ Se originó como una propuesta de Reglamento francesa, con buenas expectativas, pero no logró alcanzar el consenso necesario para ser una medida plenamente comunitaria; extiende los derechos de circulación de corta duración a personas que se les ha concedido un permiso de larga duración por un Estado miembro pero que aún no ha recibido un permiso de residencia. El proyecto de informe del Parlamento Europeo sobre esta medida cuestiona la base jurídica propuesta por la Presidencia (arts. 62(2) (b) ii y 63 (3) (a) TCE). Esta iniciativa es sin dudas, bienvenida, ya que ampliará el ámbito de las personas que tienen derecho a viajar en la Comunidad. Es, particularmente, apropiado ampliar el derecho de viaje a personas a la espera de una prueba de un permiso de residencia, ya que las autoridades nacionales no siempre expiden un permiso a los titulares de un visado de larga duración en su debido tiempo.

${ }^{85}$ DOCE L 150 de 06.06.2001.Véase, su versión más reciente, en Decisión del Consejo de 22 de diciembre de 2003 DOCE L 5/79 9.1.2004 pp.79-80.

${ }^{86}$ CHUECA SANCHO, A. “Trascendencia del Manual Común y de la Instrucción Consular Común en la Inmigración a la Unión Europea" 1 Sesión INTERMIGRA 16 de junio de 2005. 


\section{LA INCIPIENTE REGULACIÓN UNASUR EN MATERIA MIGRATORIA}

La migración representa un objetivo específico prioritario para la Organización, ${ }^{87}$ y ya se ha visto como ha existido una voz propia latinoamericana que rechazó la directiva de retorno impulsada por la Unión Europea ${ }^{88}$ o el impulso al Convenio sobre los derechos de los trabajadores migrantes y sus familiares, unido a un ambicioso plan de estudio conocido como Proceso de Lima que reúne trabajos sobre principios y normas aplicables a las migraciones internacionales. A nivel práctico, ha sido la alta actividad turística del continente la que ha empujado a los ministros de Turismo de UNASUR a plantear la posibilidad de un modelo común de visado de aplicación al territorio que comprenden las Repúblicas de la Unión de Naciones Sudamericanas, como un instrumento que facilitaría el turismo interestatal, y los recursos obtenidos por su emisión podrían servir como recurso propio de la Organización, por su alto simbolismo como semilla de " presupuesto común latinoamericano " siguiendo el modelo de la Unión Europea. Asimismo, tendría una vocación política por su simbología y como frente común frente a las políticas restrictivas de entrada de los Estados Unidos de América y de la Unión Europea, como un gran bloque político y económico que en base al principio de reciprocidad aplique las mismas normas que estos y en segunda instancia se proteja a los connacionales del continente junto a la figura del pasaporte UNASUR. Estas medidas sin duda servirían para avanzar en la construcción de una ciudadanía sudamericana mediante el libre tránsito de personas en un espacio de fronteras abiertas, con dos espacios públicos, aquellos de los ciudadanos y el de extranjeros residentes o turistas.

Este documento tendría un registro electrónico y agilizaría el ingreso en los países y serviría como control minucioso de ingresos y salidas, evitando flujos migratorios incontrolados, conservando el historial del visitante, sus datos personales, y su ocupación.

En cualquier caso, visto lo enrevesado y la rigidez del procedimiento europeo, UNASUR a través de sus cancillerías de relaciones exteriores e interior debe establecer un Consejo de seguridad con competencia para la concesión de visados en función de los avatares de la política exterior, y un procedimiento transparente de recursos para las solicitudes no admitidas ${ }^{8}{ }^{8}$ Los Estados que no deseen participar en este proceso de integración en materia de visados también podrán excluirse a través de fórmulas de geometría variable, mediante la adopción de protocolos semejantes a los europeos. De hecho ya existe un laboratorio de cooperación reforzada como lo muestra los avances en el terreno Mercosur, con la adopción a principios del 2000, de acuerdos de exención de visados, o la creación de la " Visa Mercosur," cómo proceso intermedio que tenderá a extenderse a otros países asociados, a semejanza de lo ocurrido con Schengen. ${ }^{90}$

Por último hay que destacar un actor esencial para este proceso, la Conferencia Sudamericana sobre Migraciones como un foro regional de diálogo.

\footnotetext{
${ }_{87}$ En detalle, véase, Díaz Barrado, C.M. " La Comunidad Suramericana de Naciones: propuestas y realizaciones " Revista española de Derecho internacional vol. 57 n. 2 (2005).

${ }^{88}$ Véase, Júarez V.; Zully, L. Gainza P. (2008). Conferencia. Causas y consecuencias de las nuevas políticas de retorno forzado en los derechos de las personas migrantes. Grupo de trabajo Migraciones de la Plataforma Interamericana de Derechos Humanos, Democracia y Desarrollo, III Foro Social Mundial de las Migraciones, Madrid 12 de septiembre.

${ }^{89}$ Con base en el modelo del Sistema de Información de Visados Europeos (VIS).

${ }^{90}$ Cfr, Chueca Sancho, A." Libre circulación de personas en Sudamérica. Una aproximación " Revista electrónica iberoamericana vol. 2 n. 12008 http://www.mintra.gob.pe/migrante/pdf/Libre_circulacion_en_Suramerica.pdf
} 
Estos avances llevaran a una nueva dimensión la figura tradicional del asilo sostenida como una costumbre regional en el continente desde la década de los cincuenta y ampliamente debatida en la actualidad, ofreciendo una cobertura jurídica a través de un cordón de soberanías unidas, al mismo tiempo establecerá un modelo de sociedad de Derecho en torno a ciudadanos y residentes válido para el discurso político de una ciudadanía común latinoamericana.

\section{CONCLUSIONES}

La situación de la regulación de los visados a nivel de la Unión Europea aún no se encuentra plenamente comunitarizada lo que repercute en un amplio déficit democrático y en el secretismo en el que adoptan las decisiones de inclusión o no de los nacionales de terceros países en listas blancas, grises o negras que se complica por un proceso claramente opaco a la hora de impugnar estas decisiones; en la actualidad, un ejemplo de este proceso lo encontramos en la posición de España que propugna la flexibilización de la entrada de ciudadanos colombianos en el territorio Schengen y que en el pasado cercano produjo numerosos roces con dirigentes políticos y miembros destacados de la comunidad literaria colombiana que consideraron la falta de apoyo de España como una traición por la Madre patria. Es por ello, que el proceso UNASUR se encuentra a tiempo de crear un modelo más humano de control de fronteras donde quede garantizada la seguridad nacional y al mismo tiempo los derechos de los extranjeros, en este sentido muchos de las repúblicas latinoamericanas han ratificado el Convenio de Naciones Unidas sobre protección del trabajador migrante y sus familiares en cuyo ámbito material se encuentra la humanización del proceso de entrada y residencia en un país distinto a aquel de su nacionalidad.

7. BIBLIOGRAFÍA SELECCIONADA

BOU FRANCH, V., Derechos Humanos Selección Básica de Textos Internacionales (comp.) Editorial, Tirant lo Blanch, 2003.

CARRERA HERNÁNDEZ, F.J. NAVARRO BAUTISTA, N., El Espacio de libertad, seguridad y justicia en la Unión Europea. Textos fundamentales, Tecnos, 1999.

ESPADA RAMOS, M. L., “Asilo e Inmigración en la Unión Europea”, Revista de estudios políticos núm. 86 oct-dic., 1994.

MANGAS MARTIN, A., "El Tratado de la Unión Europea”, Gaceta Jurídica de la Unión Europea. 2 vols. 1992.

MUÑOZ AUNIÓN, A., La Política común europea de derecho de asilo. Editorial Tirant lo Blanch, 2006.

NAFZINGER, J., “The General Admission of Aliens under International Law” American Journal of International Law vol. 77/41.

REMIRO BROTONS, A."La Naturaleza de la Comunidad Europea, sus Competencias, Instituciones, y Sistema de Adopción de Decisiones en el Proceso de Integración”. www. CEFIR.org.uy/docs/dto4/13remir1.html 
VALLE GÁLVEZ, A.,"La refundación de la libre circulación de personas, Tercer Pilar y Schengen: el espacio europeo de libertad, seguridad y justicia" RDCE núm. 3 enero/ junio 1998.

WITHOL DE WENDEN, C., "Refugié politique: une notion en crise”, Esprit mayo 1990. 